\title{
Preparation of silicon carbide rod-like structures by drying droplet and autoclave methods
}

\author{
A.V. Tuchin ${ }^{\dagger}$, D.A. Zhukalin, L.A. Bityutskaya, A.V. Kalashnikov \\ †a.tuchin@bk.ru
}

Voronezh State University, Universitetskaya pl. 1, 394006, Voronezh, Russia

Preparation of silicon carbide by traditional methods involves considerable energy and economic costs, so the search for alternative technologies of the synthesis is of the great interest. Carbon nanomaterials are actively investigated as a carbon source to reduce the temperature of synthesis. This paper presents the results of an experimental study of the morphology, elemental composition and crystal structure of structures obtained from colloidal solutions of short $(l \sim 500 \mathrm{~nm})$ carbon nanotubes and nano-sized $(\sim 7 \mathrm{~nm})$ amorphous silicon dioxide by drying droplet and autoclave methods. The formation of rod-like structures was revealed at certain critical concentrations of initial components. It was found that the dynamic conditions of the drying droplets determine a synthesis of rod-like structures at room temperature at $2-3$ times larger than at the autoclave at a temperature of about $180^{\circ} \mathrm{C}$. The elemental analysis of samples showed a high percentage of carbon and silicon atoms. The presence of the polytype $4-\mathrm{H}$ SiC phase in the rod-like structures was revealed by the X-ray diffractometry. A model of the active charged center of short carbon nanotubes that provides the possibility of Si-C, Si-O-C and $\mathrm{C}-\mathrm{Si}-\mathrm{O}-\mathrm{C}$ covalent bonds formation was offered based on numerical calculations. The drying droplet method is suitable for a quick (10 - 20 minutes) local synthesis of a small amount of rod-like structures with a minimum energy consumption. The autoclave allows to synthesize gram quantities for a long time (a few days). Both methods are low temperature in the comparison with the widely used in practice.

Keywords: silicon carbide, drying droplet method, autoclave, short carbon nanotube, active center.

\section{Получение стержневых структур карбида кремния капельным и автоклавным методами}

\author{
Тучин А.В. ${ }^{\dagger}$, Жукалин Д.А., Битюцкая Л.А., Калашников А.В. \\ †a.tuchin@bk.ru
}

Воронежский государственный университет, Университетская пл. 1, 394006, Воронеж, Россия

Получение карбида кремния и керамики на его основе традиционными методами сопряжено со значительными энергетическими и экономическими затратами, поэтому поиск альтернативных технологий синтеза данного полупроводникового соединения представляет большой интерес. С целью снижения температуры синтеза активно исследуются углеродные наноматериалы в качестве источника углерода. В настоящей работе представлены результаты экспериментального исследования морфологии, элементного состава и кристаллического строения структур, полученных капельным и автоклавным методами из коллоидных растворов коротких $(l \sim 500$ нм $)$ углеродных нанотрубок и наноразмерного ( 7 нм) аморфного пиролитического диоксида кремния. Установлено формирование стержневых структур при определенных критических концентрациях исходных компонентов. Обнаружено, что динамические условия высыхающей капли определяют синтез при комнатной температуре стержневых структур в 2 - 3 раза больших размеров, чем при синтезе в автоклаве при температуре $\sim 180^{\circ} \mathrm{C}$. Элементный анализ показал высокое процентное содержание углерода и кремния в стержневых структурах. Дифрактометрические исследования показали наличие фазы карбида кремния политипа 4-H SiC в синтезированных стержневых структурах. Основываясь на квантово-химических расчетах предложена модель активного заряженного центра коротких углеродных нанотрубок, обеспечивающих возможность формирования ковалентных связей Si-C, O-C и C-Si-O-C при взаимодействии с аморфным диоксидом кремния. Капельный метод подходит для быстрого (10-20 мин) локального синтеза небольшого количества стержневых структур при минимальных затратах энергии. Автоклав позволяет синтезировать граммовое количество стержневых структур за достаточно длительное (несколько суток) время. Оба метода в сравнении с широко используемыми на практике являются низкотемпературными.

Ключевые слова: карбид кремния, капельный метод, автоклав, короткая углеродная нанотрубка, активный центр. 


\section{1. Введение}

Карбид кремния - широкозонный полупроводник с высокой температурной стабильностью, механической и химической прочностью, что позволяет электронным устройствам на карбидкремниевой базе функционировать в экстремальных условиях [1-3]. Химическая инертность данного полупроводникового соединения и высокая температура плавлениякристаллизации определяют высокую температуру синтеза от $2400^{\circ} \mathrm{C}$ (метод Ачиссона, Лели и M-PVT), до $1000^{\circ} \mathrm{C}$ (LPCVD метод) [3-6]. Получение карбида кремния и керамики на его основе традиционными методами, сопряжено со значительными энергетическими и экономическими затратами, поэтому поиск альтернативной технологии синтеза $\mathrm{SiC}$ представляет большой интерес.

Современные способы получения монокристаллического карбида кремния преимущественно базируются на CVD - методе $[3,5,6]$ и предполагают термическое разложение газообразных компонентов, содержащих углерод и кремний в связанном состоянии (например, бутан, силан или дисилан), с последующим осаждением образовавшихся радикалов на монокристаллическую затравку, в качестве которой, как правило, используется карбид кремния или сапфир. При этом образуется карбид кремния одной из многочисленных политипных форм, всего которых насчитывают более 250 [7]. Недавно реализован рост эпитаксиальных пленок $\mathrm{SiC}$ за счет топохимической реакции монокристаллического кремния с газообразным СО [8-10]. Расчетом фазовой диаграммы давление - поток показано, что бездислакационный $\mathrm{SiC}$ растет в условиях далеких от термодинамического равновесия фаз (давление СО меньше в 2-3 раза, большой поток газа), определяющих сохранение кремниевых вакансий [11].

С целью снижения температуры синтеза карбида кремния и композитных материалов на его основе активно исследуются углеродные наноматериалы в качестве источника углерода [12-21]. Например, в работе [20] методом CVD синтезировали композит Si-C пропусканием паров кремний содержащих соединений через массив ориентированных углеродных нанотрубок при температуре $580-700^{\circ} \mathrm{C}$. Дальнейшее снижение энергетических и экономических затрат на синтез карбида кремния может быть достигнуто как увеличением концентрации активных атомов углерода, так и заменой источника кремния на наноразмерную форму. В коротких углеродных нанотрубках количество неэквивалентных положений адсорбции значительно больше, чем в длинных ( $l \sim$ мкм) [22]. Это открывает возможности реализации новых механизмов локального взаимодействия коротких УНТ с наноразмерными материалами различной природы. Одним из доступных кремний содержащих материалов является пиролитический диоксид кремния. В последнее время активно исследуются магнитные и люминесцентные свойства наноразмерного $\mathrm{SiO}_{2}$ и интерфейсов $\mathrm{SiO}_{2} / \mathrm{Si}$ для разработки материалов новейших оптических и спинтронных устройств [22-25].
Структурная эволюция высыхающих капель коллоидных растворов представляет собой комплекс сложных физико-химических и механических процессов, объединяемых понятием дегидратационная самоорганизация [26]. Поэтому высыхающая капля рассматривается как нанореактор с динамическими стенками $[27,28]$ и с постоянно меняющимися параметрами: концентрация, радиус кривизны, поверхностное натяжение, температура [29, 30]. Возрастание давления способствует появлению мощных турбулентных потоков внутри капли, что, совместно с броуновским движением, приводит к многократным столкновением частиц, образованием тепловых автоволновых пространственно-временных структур, являющихся характеристикой процесса самоорганизации [31]. В настоящее время капельный метод широко применяется на практике в задачах идентификации веществ, диагностики заболеваний, для синтеза композитных и гибридных материалов [26, 32, 33].

В настоящей работе исследован процесс взаимодействия коротких углеродных нанотрубок ( $l \sim 500$ нм) с наноразмерным ( 7 нм) аморфным диоксидом кремния при смешивании их коллоидных растворов в автоклаве и высыхающей капле.

\section{2. Основные результаты}

Коллоидные взвеси УНТ и аморфного диоксида кремния предварительно диспергировались в ультразвуковой ванне 15 мин. Затем капли наносились на гидрофильную горизонтальную подложку. Высыхание капли проводилось при комнатной температуре. Исследование морфологии структур, полученных капельным методом, проводилось сканирующим электронным микроскопом JSM-6390LV (JEOL, Япония).

При смешивании коллоидных взвесей с определенными критическими концентрациями компонентов обнаружено формирование стержневых структур диаметром 200-250 нм, длиной 4 мкм (рис. 1) примерно в 8 раз превосходящие по размеру исходные УНТ. Отдельные нанотрубки не выявлены, что важно для синтеза стабильных композитных материалов [26]. По результатам элементного анализа полученных структур (аналитическая приставка Bruker AXS Microanalysis GmbH (Германия)) соотношение атомных концентраций Si:O:C составляет 55.3:15.9:23.4, прочее - 5.4 ат. \%, что указывает на высокое процентное содержание кремния и углерода в образцах. В исходном аэросиле процентное соотношение Si к O составляло 1:2.

Изменение атомных концентраций может свидетельствовать о фазовых превращениях в исходных компонентах. Например, в работе Гуськовой [34] показано, что при концентрации избыточных атомов $\mathrm{Si}$ в $\mathrm{SiO}_{2}$ на уровне $\sim 2$ at. \% возможно формирование кремниевых нановключений. При взаимодействии УНТ с оксидами металлов, такими как олово и вольфрам, обнаружено формирование оксикарбидных и карбидных фаз [35-37].

Дифрактометрические исследования стержневых структур проводились в режиме отражения на дифрактометре PANalytical EMPYREAN с использовани- 
ем излучения $\mathrm{Cu} \mathrm{K} \alpha 1$ и позиционно-чувствительного детектора PIXcel1D, диапазон измерения $2 \theta$ составляет $5-60^{\circ}$, шаг $-0.013^{\circ}$. Индицирование дифрактограмм проводилось с использованием программ ITO и TREOR. Результаты анализа экспериментальных порошковых дифрактограмм показали наличие фазы карбида кремния со структурой $4 \mathrm{H}-\mathrm{P} 63 \mathrm{mc}$, параметры решетки $a=b=3.081 \AA, c=10.060 \AA$ (табл. 1).

Синтез в автоклаве проводился по следующей схеме. Коллоидный раствор аморфного диоксида кремния перемешивался в магнитной мешалке, добавлялась обработанная ультразвуком взвесь УНТ. Полученная смесь переливалась в тефлоновый химический стакан, который устанавливался в автоклав. Синтез проводился в печке при температуре $175^{\circ} \mathrm{C}$ в течение 336 ч при постоянном вращении. Вскрытие автоклава проводилось после охлаждения до комнатной температуры. Содержимое про-

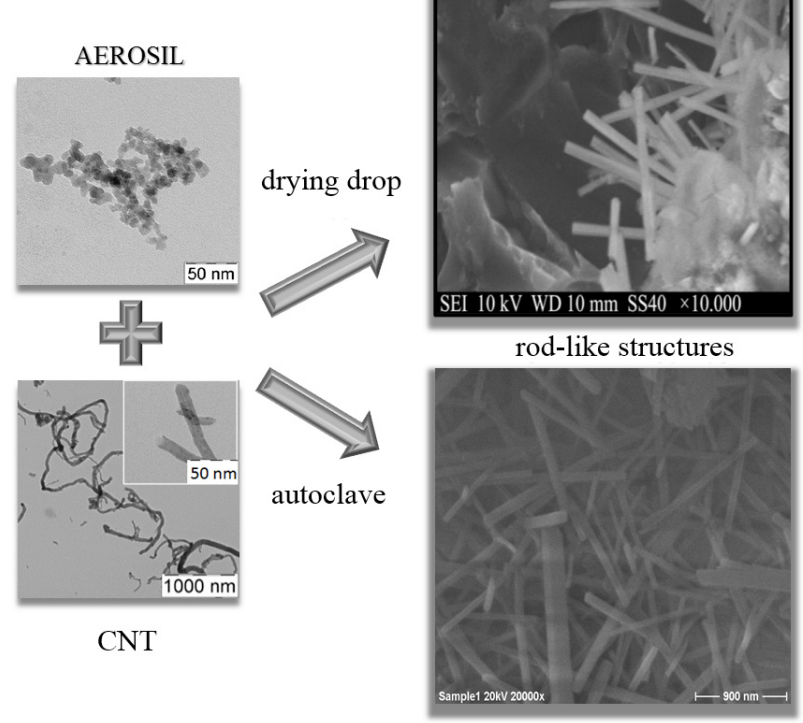

Рис. 1. Исходные компоненты (пиролитический диоксид кремния марки AEROSIL и углеродные нанотрубки) и полученные капельным автоклавным методами стержневые структуры.

Fig. 1. The initial components (pyrolytic silicon dioxide brand AEROSIL and carbon nanotubes) and the resulting rod-like structure obtained by droplets and autoclave methods.

табл. 1. Угловое положение дифракционных пиков стержневых структур.

Table 1. The angular position of the diffraction peaks of rod-like structures.

\begin{tabular}{|c|c|c|c|}
\hline № & $2 \theta,{ }^{\circ}$ & $d, \AA$ & $\begin{array}{c}\text { intensity, \% } \\
\text { интенсивность, \% }\end{array}$ \\
\hline 1 & 33.550 & 2.66894 & 27.22 \\
\hline 2 & 34.761 & 2.57881 & 96.92 \\
\hline 3 & 35.671 & 2.51482 & 71.01 \\
\hline 4 & 38.149 & 2.35716 & 100 \\
\hline 5 & 43.294 & 2.08823 & 90.31 \\
\hline
\end{tabular}

мывалось дистиллированной водой и фильтровалось с помощью фильтровальной бумаги и водоструйного вакуумного насоса. Образец высушивался в термошкафу в течение суток при температуре $105^{\circ} \mathrm{C}$.

Исследование морфологии поверхности синтезированных в автоклаве образцов проводилось сканирующим электронным микроскопом Hitachi S-3200N (Япония) при ускоряющем напряжении 20 кВ. При определённых критических концентрациях аморфного диоксида кремния и УНТ обнаружено формирование стержневых структур, аналогичных, полученным капельным методом (рис. 1). Преобладающий диаметр составляет 90 нм, имеется небольшая доля структур диаметром 250 нм, длина варьируется от 1.2 до 4 мкм. На всех исследуемых масштабах отдельные УНТ не обнаружены. При синтезе капельным методом концентрация компонентов растет, в автоклаве коллоидные растворы остаются разбавленными, что определяет меньшие в 3-4 раза размеры основной фракции стрежневых структур, синтезированных в автоклаве.

Время высыхания капли при комнатной температуре составляет 15 мин. Поэтому капельный метод подходит для быстрого (10-20 мин) локального синтеза небольшого количества наноструктур при минимальных затратах энергии. Автоклав позволяет синтезировать граммовое количество стержневых структур при достаточно длительном (несколько суток) времени синтеза и температуре $\sim 180^{\circ} \mathrm{C}$. Оба метода в сравнении с широко используемыми на практике являются низкотемпературными.

Ранее при теоретическом исследовании электронной структуры нанотрубок нами была показана топологическая реакционная способность коротких УНТ. Селективность взаимодействия атомов и радикалов с атомами углерода заряженного интерфейса на границе шапка/цилиндрический остов нанотрубки отражается в изменении энергии ковалентных связей до \pm 0.5 эВ $[22,33]$. Установлено формирование ковалентных связей $\mathrm{Si}-\mathrm{C}$ и O-C и мостиков C-Si-O-C при критическом расстоянии кремний-углерод менее $1.94 \AA$ А. Формирование ковалентных связей атомов кремния с атомами углерода шапки энергетически выгоднее, чем с атомами углерода цилиндрического остова нанотрубки. Повышенная реакционная способность шапок позволяет рассматривать их в качестве активного центра нанотрубок и открывает технологическую возможность низкотемпературного синтеза высокотемпературных соединений.

Из результатов расчетов следует, что увеличение длины нанотрубок уменьшает концентрацию активных атомов углерода. Данный результат получил экспериментальное подтверждение. Формирование стержневых структур не выявлено при замене коротких УНТ на нанотрубки длиной более 1 мкм. В этом случае морфология образцов, полученных капельным и автоклавным методами аналогична исходному пиролитическому диоксиду кремния с незначительным изменением распределения частиц по размеру. Выявлены многочисленные отдельные УНТ, что указывает на слабое взаимодействие длинных нанотрубок с наноразмерным диоксидом кремния. 


\section{3. Заключение}

Топологическая реакционная способность коротких нанотрубок определяет наличие взаимодействия при смешивании их коллоидных растворов и пиролитического диоксида кремния. Обнаружено формирование стержневых структур диаметром 90-300 нм и длиной $1.2-4$ мкм при синтезе капельным и автоклавным методами. Дифрактометрические исследования синтезированных капельным методом стержневых структур показали наличие фазы карбида кремния 4Н-P63mc. Выявлена роль динамических условий в высыхающей капле на морфологию полученных структур: нарастающая концентрация компонентов определяет синтез более крупных стержневых структур.

Благодарность/Acknowledgements. Работа выполнена при финансовой поддержке РФФИ, проект 16-43-360281 p_a.

\section{Литература/References}

1. V. Vojtovich, A. Gordeev, A. Dumanevich. Silovaya ehlektronika. 5, 4-10 (2010). (in Russian) [В. Войтович, А. Гордеев, А. Думаневич. Силовая электроника. 5, $4-10(2010)]$.

2. I. SHahnovich. EHlektronika: Nauka, Tekhnologiya, Biznes. 4, $12-18$ (2005). (in Russian) [И. Шахнович. Электроника: Наука, Технология, Бизнес. 4, $12-18$ (2005)].

3. O. A. Ageev, A.E. Belyaev, N.S. Boltovec, et al. Karbid kremniya: tekhnologiya, svojstva, primenenie. Har'kov, ISMA. (2010) 532 p. (in Russian) [O.A. Агеев, А.Е. Беляев, Н.С. Болтовец и др. Карбид кремния: технология, свойства, применение. Харьков. ИСМА. (2010) 532 c.

4. S.N. Gusev, S.Yu. Zubkov, S.A. Levchuk, and M.V. Sapozhnikov. Journal of Surface Investigation. Xray, Synchrotron and Neutron Techniques. 4 (3), 374 - 378 (2010). (in Russian) [С. Н. Гусев, С. Ю. Зубков, С.А. Левчук, М.В. Сапожников. Поверхность. Рентгеновские, синхротронные и нейтронные исследования. 5, 10 - 17 (2010)].

5. A.V. Semenov, V.M. Puzikov, E.P. Golubova, et al. Semiconductors. 43 (5), 685-689 (2009). (in Russian) [А.В. Семенов, В.М. Пузиков, Е.П. Голубова и др. Физика и техника полупроводников. 43 (5), 714 - 718 (2009)].

6. D. O. Moskovskih. Poluchenie submikronnogo poroshka karbida kremniya i nanostrukturirovannoj keramiki na ego osnove: Dissertacija na soiskanie stepeni kandidata tehnicheskih nauk. Moskva. 2015. 166 p. (in Russian) [Д.О. Московских Получение субмикронного порошка карбида кремния и наноструктурированной керамики на его основе: дисс. канд. техн. наук. Москва. 2015. 166 с.].

7. V.A. Soltamov, D. O. Tolmachev, I. V. Il'in, et al. Physics of the Solid State. 57 (5), $891-899$ (2015). (in Russian) [В.А. Солтамов, Д.О. Толмачев, И.В. Ильин и др. ФTT. 57 (5), 877 - 885. (2015)].
8. S.A. Kukushkin, A.V. Osipov. Journal of Applied Physics. 113, 024909 (2013). DOI: http://dx.doi.org/10.1063/1.4773343

9. S. A. Kukushkin, A. V. Osipov, N. A. Feoktistov. Physics of the Solid State. 56 (8), $1507-1535$ (2014). (in Russian) [С. А. Кукушкин, А. В. Осипов, Н. А. Феоктистов. ФТТ 56 (8), $1457-1485$ (2014)].

10. S.A. Kukushkin, A.V. Osipov. Journal of Physics D: Applied Physics. 47 (13), 313001 (2014). DOI: http://dx.doi.org/10.1088/0022-3727/47/31/313001

11. S. A. Kukushkin, A. V. Osipov. Physics of the Solid State. 58 (4), 747 - 751. (2016). (in Russian) [С. А. Кукушкин, А. В. Осипов. ФТТ. 58 (4), 725 (2016)].

12. L. Wang, H. Wada, L.F. Allard. Journal of Materials Research. 7 (1), 148 - 163 (1992). DOI: http://dx.doi.org/ $10.1017 /$ S0884291400096813.

13. W.-S. Seo, K. Koumoto. Journal of the American Ceramic Society. 79 (7), $1777-1782$ (1996). DOI: 10.1111/j.1151 - 2916.1996.tb07995.x

14. Y.J. Wu, W. Qin, Z.X. Yang, et al. Journal of Materials Science. 39 (16), 5563 - 5565 (2004).

15. J. Wei, K.-Z. Li, H.-J. Li, et al. Materials Chemistry and Physics. 95 (1), $140-144$ (2006). DOI:10.1016/j. matchemphys.2005.05.032

16. Y. J. Wu, J. S. Wu, W. Qin, et al. Materials Letters. 58 (17-18), 2295 - 2298 (2004). DOI:10.1016/j.matlet.2004.03.002

17. F.-L. Wang, L.-Y. Zhang, Y.-F. Zhang. Nanoscale Research Letters. 4, 153-156 (2009). DOI: 10.1007/s11671-008-9216-3

18. J.-S. Lee, Y.-K. Byeun, S.-H. Lee, and S.-C. Choi. Journal of Alloys and Compounds. 456 (1-2), $257-263$ (2008). DOI: $10.1016 /$ j.jallcom.2007.02.010

19. M. Mukherjee. Silicon Carbide - Materials, Processing and Applications in Electronic Devices. InTech. 2011. 558 p. DOI: $10.5772 / 852$.

20. J. Guo, A. Sun, X. Chen, et al. Electrochimica Acta. 56 (11), $3981-3987$ (2011). DOI: 10.1016/j. electacta.2011.02.014.

21. D.A. Zhukalin, A.V. Tuchin, D.L. Goloshchapov, and L.A. Bityutskaya. Technical Physics Letters. 41 (2), $157-159$ (2015). (in Russian) [Д.А. Жукалин, А. В. Тучин, Д. Л. Голощапов, Л. А. Битюцкая. Письма ЖТФ. 41 (4), $1-6$ (2015)].

22. A.V. Tuchin, V.A. Tyapkina, L.A. Bityuckaya. Kondensirovannye sredy i mezhfaznye granicy. 17 (4), 552-559 (2015). (in Russian) [A. В, Тучин, В.А. Тяпкина, Л.А. Битюцкая. Конденсированные среды и межфазные границы. 17 (4), 552 - 559 (2015)].

23. V. G. Il'ves, M. G. Zuev, S. Yu. Sokovnin, A. M. Murzakaev. Physics of the Solid State. 57 (12), $2512-2518$ (2015). (in Russian) [В. Г. Ильвес, М. Г. Зуев, С. Ю. Соковнин, А. М. Мурзакаев. ФТТ. 57 (12), 2439 - 2445 (2015)].

24. L. Oakes, A. Westover, J. W. Mares, et al. Scientific Reports. 3. 3020 (7) (2013). DOI: 10.1038/srep03020.

25. E. Sun, F. - H. Su, Y. - T. Shih, et al. Nanotechnology. 20 (44). 445202 (2009). DOI: http://dx.doi.org/10.1088/095 $7-4484 / 20 / 44 / 445202$.

26. T. A. Yakhno, V.G. Yakhno. Technical Physics. 54 (8), 1219 - 1227 (2009). (in Russian) [Т. А. Яхно, В. Г. Яхно. ЖТФ. 79 (8), 133 - 141 (2009)]. 
27. B. Su, S. Wang, Y. Song, and L. Jiang. Nano Research. 4 (3), 266-273 (2011). DOI: 10.1007/s12274-010-0078-5.

28. R. Duggal, F. Hussain, M. Pasquali. Advanced Materials. 18 (1), 29 - 34 (2006). DOI: 10.1002/adma.200690004.

29. T. A. Yakhno, O. A. Sanina, M. G. Volovik, et al. Technical Physics. 57 (7), 915 - 922 (2012). (in Russian) [T. А. Яхно, О.А. Санина, М. Г. Воловик и др. ЖТФ. 82 (7), 22 - 29 (2012)].

30. T. A. Yakhno, V.V. Kazakov, O. A. Sanina, et al. Technical Physics. 55 (7), 929 - 935 (2010). (in Russian) [T. A. Яхно, В. В. Казаков, О.А. Санина и др. ЖТФ. 80 (7), 17 - 23 (2010)].

31. L.A. Bityuckaya, D.A. ZHukalin, A. V. Tuchin, et al. Kondensirovannye sredy i mezhfaznye granicy. 16 (4), 425-430 (2014). (in Russian) [Л.А. Битюцкая, Д.А. Жукалин, А. В. Тучин и др. Конденсированные среды и межфазные границы. 16 (4), 425 - 430 (2014)].

32. D.A. ZHukalin, A.V. Tuchin, L.A. Bityuckaya, E. N. Bormontov. Vestnik VGU «Fizika. Matematika». 3, 5-20 (2014). (in Russian) [Д. А. Жукалин, А. В. Тучин, Л.А. Битюцкая, Е.Н. Бормонтов. Вестник ВГУ «Физика. Математика». 3, 5-20 (2014)].

33. D. Zhukalin, A. Tuchin, D. Goloshchapov, L. Bityutskaya,
F. Roessner. Kondensirovannye sredy i mezhfaznye granicy. 16 (4), 431 - 438 (2014). (in Russian) [D. Zhukalin, A. Tuchin, D. Goloshchapov, L. Bityutskaya, F. Roessner. Конденсированные среды и межфазные границы. 16 (4), 431 - 438 (2014)].

34. O.P. Gus'kova, V.M. Vorotyntsev, N.D. Abrosimova, et al. Physics of the Solid State. 57 (11). 2164-2169 (2015) (in Russian) [О.П. Гуськова, В. М. Воротынцев, Н.Д. Абросимова и др. ФТТ. 57 (11). 2106-2111 (2015)].

35. A.I. Kirillov, A.M. Obyedkov, V.A. Yegorov, et al. Nanotechnics. 1 (25), $72-77$ (2011). (in Russian) [А.И. Кириллов, А.М. Объедков, В.А. Егоров и др. Нанотехника. 1 (25), 72 - 77 (2011)].

36. V. N. Sivkov, A. M. Ob"edkov, O. V. Petrova, et al. Physics of the Solid State. 57 (1), 197 - 204 (2015). (in Russian) [В.Н. Сивков, А.М. Объедков, О.В. Петрова и др. ФTТ. 57 (1), 185 - 191 (2015)].

37. V.V. Bolotov, S.N. Nesov, P.M. Korusenko, S.N. Povoroznyuk. Physics of the Solid State. 56 (9), 1899-1903 (2014). (in Russian) [В.В. Болотов, С. Н. Несов, П. М. Корусенко, С. Н. Поворознюк. ФТТ. 56 (9), $1834-1838$ (2014)]. 